\title{
Pleurotus türlerinde hasat sonrası uygulamaların kaliteye etkisi
}

\section{The effect of quality of post-harvest treatments in Pleurotus species}

\author{
Selen AKAN $^{1 *}$ (D), Ruhsar YANMAZ ${ }^{1}$ iD \\ ${ }^{1}$ Ankara Üniversitesi Ziraat Fakültesi Bahçe Bitkileri Bölümü 06110 Dışkapı/Ankara
}

To cite this article:

Akan, S. \& Yanmaz, R. (2018). Pleurotus türlerinde hasat sonrası uygulamaların kaliteye etkisi. Harran Tarım ve Gida Bilimleri Dergisi, 22(3): 445-453. DOI: 10.29050/harranziraat.3323 21

Address for Correspondence: Selen AKAN

e-mail:

sakan@agri.ankara.edu.tr

Received Date:

02.08.2017

Accepted Date:

08.02.2018
(C) Copyright 2018 by Harran University Faculty of Agriculture. Available on-line at www.dergipark.gov.tr/harranziraat

This work is lisensed under a Creative Nonmons AttributionNon Commercial öz

Yeryüzünde doğal olarak yetişen binlerce mantar türü bulunmaktadır. Bu türlerden kültüre alınan ve Dünya'da yaygın üretimi yapılabilen mantar türleri Agaricus bisporus, Pleurotus spp., Lentinula edodes ve Flammulina velutipes'dir. Ülkemizde de Agaricus bisporus'tan sonra en çok üretimi yapılan mantarlar Pleurotus spp. türleridir. Bu mantarlar beslenme ve insan sağlığı yönünden önemlidir. Ancak diğer mantarlarda olduğu gibi hasat sonrası ömürleri kısadır. Hasat sonrası ömrün kısa olmasında ve kalite kayıplarının artmasında sıcaklık, nem ve hava ortamının bileşimi etkilidir. Kalite kayıplarını azaltabilmek ve muhafaza süresini uzatmak için farklı muhafaza tekniklerinin yanında kimyasal uygulamalar da kullanılmaktadır. Bu derlemede Pleurotus spp. türlerinde mantarın hasat sonrası ömrünün uzatılmasında kullanılan uygulamaların kalite üzerine etkisi konusunda yapılan araştırma sonuçları dikkate alınarak değerlendirilmiştir.

Anahtar Kelimeler: Mantar, Pleurotus spp., Muhafaza, Kalite

\section{ABSTRACT}

There are thousands of species of mushroom that naturally grow on the earth. Among these, the mushroom that can be widely produced in the world are Agaricus bisporus, Pleurotus spp., Lentinula edodes and Flammulina velutipes. In our country, the most produced mushrooms are Pleurotus spp. after Agaricus spp. These mushrooms are important for nutrition and human health. However, their postharvest life is short like the other mushrooms. The short-lived postharvest life and the increase in quality losses during the storage are caused by the temperature, humidity and ventilation. In addition to the different storage techniques, chemical applications are also used to reduce quality losses and prolong storage time. In this review, the results of the research on the effect of treatments on the quality of Pleurotus spp. species used for the extension of the postharvest life were evaluated.

Key Words: Mushroom, Pleurotus spp., Storage, Quality 


\section{Giriş}

Yenilebilir mantar türleri, zengin besin içerikleri, kendilerine özgü aromaları ile hem taze hem de işlenmiş olarak tüketilebilen ve beslenme için gerekli olan ürünlerden biridir. Dünya genelinde 20 'den fazla yetiştiriciliği yapılan mantar türü bulunmaktadır. Bunlardan yaygın olarak kullanılanlar arasında ilk sırayı Agaricus bisporus almakta, bunu Pleurotus spp., Lentinula edodes ve Flammulina velutipes izlemektedir (Gogavekar ve ark., 2012; Kalac, 2012).

Ülkemiz florası da doğal olarak yetişen ve kültüre alınmış mantarlar yönünden zengindir ve 40'tan fazla mantar türü bulunmaktadır (Anonim, 2017). 2014 yılı FAO verilerine göre, Dünya kültür mantarı üretimi 10 milyon ton civarındadır. Üretimin 7.6 milyon tonu Çin'e aittir. İtalya (600.000 ton), ABD (432.000 ton), Hollanda (310.000 ton), Polonya (254.000 ton), İspanya (149.000 ton), Fransa (108.000 ton) ve Kanada (102.000 ton) diğer kültür mantarı üreticisi ülkelerdir (FAO, 2014). Dünya mantar ihracatında ise ilk sırayı 205.000 tonla Portekiz almakta, bunu 69.000 tonla da Hollanda izlemektedir. Buna karşılık Dünya'da en fazla mantar ithal eden ülkeler 80.000 tonla Almanya ve 44.000 tonla da Fransa'dır (FAO, 2013).

Türkiye'de 2015 yılı TÜik verilerine göre 39.400 ton kültür mantarı üretimi yapılmaktadır (Anonim, 2015). Üretimde 20.000 tonla Antalya ilk sırada yer almakta, bu ilimizi 6.300 tonla Burdur, 4.360 tonla Konya ve 3.295 tonla Kocaeli izlemektedir (TÜik, 2015). Ülkemizde üretilen kültür mantarlarının çok az bir kısmı (2012 yılı: 474 ton, 2013 yılı: 301 ton) ihraç edilebilmektedir. Buna karşılık ithalat miktarı yıllara göre 0 ve 5 ton arasında değişim göstermektedir (FAO, 2013).

Günümüzde pek çok gıda maddesi besleyici değerinin yanında tıbbi değeri yönünden de değerlendirilmekte ve bir kısmı fonksiyonel gıda olarak kabul edilmektedir. Mantarlar da uzun yıllardır protein, vitamin, yağ, karbonhidrat, amino asit ve mineral maddeler ile koku ve tadı oluşturan aldehitler, alkoller, esterler, ketonlar ve kükürtlü bileşikler yönünden zengin olmaları nedeniyle fonksiyonel gida olarak da kabul edilmektedir (Stamets, 2005; Chiron ve Michelot, 2005; Elmastas ve ark., 2007; Khan ve Tania, 2012) (Çizelge 1). Ayrıca vücudu oksidatif zararlara karşı korumada etkili olan sekonder metabolitler yönünden de zengin oldukları için antioksidan kaynağı olarak değerlendirilmektedir.

Çizelge 1'den de görüldüğü gibi, Pleurotus spp. türlerinden istiridye mantarı beyaz şapkalı mantara göre protein, karbonhidrat, lif ve mineraller yönünden daha zengindir. İstiridye mantarı, besin içeriğinin yanı sıra tıbbi özellikleri ile de ön plana çıkmaktadır. Örneğin, tansiyon ve kolestrolü düşürmede, HIV virüsüne karşı korumada, diyabetin kontrolünde, karaciğeri korumada ve bağışıklık sistemini güçlendirmede oldukça etkili olduğu, antikanserojenik, antimikrobiyal, antiviral ve antialerjik özelliklere sahip olduğu belirtilmektedir (Wang ve $\mathrm{Ng}, 2004$; Li ve ark., 2008).

Besin ve sağlık değeri yüksek olan ve taze olarak tüketilen mantarların raf ömrü kısadır. Hasattan sonra 7 gün içinde hemen tüketilmesi gerekmektedir. Hasat sonrası ömrünün düşük olmasında mantarı fizyolojik ve mikrobiyolojik değişimlere ve su kaybına karşı koruyan kütikula tabakasının bulunmamasının ve hasat sonrasındaki solunum hızının yüksek oluşunun da rolü bulunmaktadır (Villaescusa ve Gil, 2003). Bununla birlikte mantarların hasat sonrasındaki kalite özellikleri bazı uygulamalarla belirli ölçüde korunabilmektedir. Bu uygulamalar arasında beyazlatma, yüksek sıcaklıkta kapalı sterilizasyon, düşük sıcaklıkta depolama, modifiye atmosferde paketleme (MAP) ve kontrollü atmosferde (KA) depolama bulunmaktadır. Bunun dışında kurutma, dondurma ve konserve yapımı sayesinde işlenmiş mantar ürünlerinin raf ömrü uzatılmakta ve yıl boyu tüketimi sağlanmaktadır.

Mantar yetiştiriciliği diğer tarım kollarına göre farklı özelliklere sahiptir. Yetiştiricilik için kontrollü koşullara sahip ve steril odaların bulunması, mantarın yetiştiriciliğinin yapıldığı ortamın özel olarak hazırlanması ve steril olması gerekmektedir. Hasadından hemen sonra hızla bozulabilen mantarların hasat sonrası depolama, 
taşıma, dağıtım ve pazarlanması sırasında sıkça sorunlar yaşanmaktadır. Bu nedenle hasat ve hasat sonrasında kalite kayıplarının belirlenip, bu kayba neden olan faktörlerin araştırılması, uygun teknikler kullanılarak kayıp düzeyinin minimuma indirilmesi önemlidir.

Çizelge 1. Agaricus spp. ve Pleurotus spp. mantarlarının besin içeriği (Anonymous, 2016).

Table 1. Nutrient content of white mushroom and oyster mushroom

\begin{tabular}{|l|c|c|}
\hline $\begin{array}{l}\text { Besin İçeriği (100 g) } \\
\text { Nutrient content (100 g) }\end{array}$ & $\begin{array}{c}\text { Agaricus spp. } \\
\text { Beyaz şapkalı mantar } \\
\text { White mushroom }\end{array}$ & $\begin{array}{c}\text { Pleurotus spp. } \\
\text { İstiridye mantarı } \\
\text { Oyster mushroom }\end{array}$ \\
\hline Enerji (Energy) (kcal) & 22.0 & 33.0 \\
\hline Su (Water) (\%) & 92.4 & 89.1 \\
\hline Protein (g) & 3.0 & 3.3 \\
\hline Karbonhidrat (Carbohydrate) (g) & 3.2 & 6.0 \\
\hline Toplam lif (Total fiber) (g) & 1.0 & 2.3 \\
\hline $\mathrm{K}$ (mg) & 318 & 420 \\
\hline P (mg) & 86 & 120 \\
\hline Mg (mg) & 9 & 18 \\
\hline Na (mg) & 5.0 & 4.9 \\
\hline Niasin (Niacin) (mg) & 3.6 & 4.9 \\
\hline
\end{tabular}

\section{Mantarlarda Hasat Sonrası Görülen Başlıca} Kalite Kayıpları

\section{a. Tekstür kaybı}

Tekstür, taze mantarların hasat sonrasındaki kalite parametrelerinden en önemlisidir. Tekstür kavramı, mantardaki yumuşama, doku sertleşmesi, süngerimsi yapı oluşumunu kapsar. En fazla görülen tekstür kaybı belirtisi yumuşamadır (Gao ve ark., 2014; Jiang ve ark., 2015). Yumuşama, mantarın tüketilen kısımları olan şapka ve sapta su kaybı ve hücrelerdeki enzimatik bozulma nedeniyle ortaya çıkar.

Depolanan mantarlarda tekstür kaybı olarak değerlendirilen doku sertleşmesi, lignin biyosentezinde yer alan fenil alanin amonyum liyaz (PAL), sinnamil alkol dehidrogenez (CAD) ve peroksidaz (POD) enzim aktivitelerinin artışıyla ligninleşmenin (lignifikasyonun) artışından kaynaklanmaktadır (Cai ve ark., 2006). Ligninleşmenin artışı ile protein ve polisakkaritlerin bozulması, hiflerin büzülmesi, merkezi vakuolün bozulması ve hücreler arası boşlukların artmasıyla, yenilen kısımlar sertleşmekte ve doku süngerimsi bir hal almakta, buna bağlı olarak çiğneme ve kesilme güçlüğü yaşanmakta, et tadı kösele gibi (kayış gibi) olmaktadır (Zivanovic ve ark., 2000; Song ve ark., 2013).

\section{b. Kararma}

Mantarda diğer pek çok meyve ve sebze türündeki gibi enzimatik ve enzimatik olmayan kararma görülür. Kahverengi, siyah ve kırmızı renk maddeleri oluşumu şeklinde ortaya çıkan enzimatik kararma; polifenol oksidaz (PPO) enzimlerinden tirozinaz enziminin aktif hale geçerek, bazı monofenollerin oksitlenmesi sonucu oluşur. Oksitlenme sonrası hücre zarının parçalanması ile şapkanın bütünlüğü kaybolur ve kararma görülür (Jolivet ve ark., 1998; Nerya ve ark., 2006). Mantardaki tirozinaz enziminin yaklaşık \%98-99'u inaktif formdadır. Aktif olan \%1-2'lik kısım, hasat sonrası yaşlanma ve enzimatik kararmaya neden olur (Brennan ve ark., 2000).

Enzimatik olmayan kararmalar bakteri kaynaklıdır. En sık rastlananı Pseudomonas tolaasii kökenli olanıdır. Bakteriler mantar şapkasının yüzeyinde kahverengi lekeler şeklinde ortaya çıkan 'bakteriyel leke' hastalığına neden olur.

\section{Hasat Sonrası Kayıpları Engellemek için Kullanılan Yöntemler}

\section{a. Düşük sıcaklıkta depolama}

Mantarların hasat sonrasında kalitelerini koruyabilmek amacıyla öncelikle düşük sıcaklıkta depolanmaları gerekmektedir. Düşük sıcaklıkta depolama solunumu yavaşlatırken, yaşlanmayı geciktirerek su kaybı ve buna bağıı buruşmayı 
engeller ve böylece raf ömrünü uzatır.

Taze mantarlar genel olarak $0^{\circ} \mathrm{C}^{\prime}$ de 8-11 gün, $4^{\circ} \mathrm{C}^{\prime}$ de 7 gün, $5^{\circ} \mathrm{C}^{\prime}$ de $4-6$ gün, $18^{\circ} \mathrm{C}^{\prime}$ de $1-3$ gün ve $20^{\circ} \mathrm{C}^{\prime}$ de 1-2 gün süre ile depolanabilmektedir (Jacobsson ve ark., 2001; Choi ve Kim, 2003; Villaescusa ve Gil, 2003). İstiridye mantarının $0^{\circ}, 4^{\circ}$ ve $7^{\circ} \mathrm{C}^{\prime}$ de muhafaza edilmesi durumunda 7 gün sonunda $\mathrm{CO}_{2}$ üretimi sıcaklığın yükselmesi ile artmıs $\left(20,39.6\right.$ ve $\left.49.2 \mu \mathrm{molCO}_{2} \mathrm{~kg}^{-1} \mathrm{~h}^{-1}\right)$, renk ve tekstürde düşük sıcaklıklarda önemli bir değişim görülmezken, yüksek sıcaklıkta tekstürde bozulma ve şapkalarda sararma görülmüştür (Villaescuse ve Gil, 2003).

\section{b. MAP ve KA'da depolama}

Mantarların hassas yapıları nedeniyle hasattan hemen sonra ambalajlanarak tüketime sunulması veya muhafazaya alınması gerekir. MAP ve KA'de depolama ile düşük sıcaklıkta depolama sırasında optimum bir atmosfer bileşimi sağlanarak iç ve dış ortam arasında dinamik bir denge oluşturulduğunda mantarın muhafaza ömrünü uzatmak mümkündür. Ambalaj ortamında (\%90 nem, $\% 1 \mathrm{O}_{2} \% 2-2,5 \mathrm{CO}_{2}$ ) mantarları 8-10 gün süre ile saklamak mümkün olabilmektedir (Briones ve ark., 1993; Popa ve ark., 1999). MAP kullanımı mantarlardaki enzimatik kararma, fermantasyon ve diğer mikrobiyolojik bozulmaları önlemede yaygın olarak kullanılmaktadır.

Ürün paketlemesinde kullanılan polimerik paketlerin ( $\mathrm{PE}, \mathrm{PP}$ veya $\mathrm{PVC}$ ), paketlenen üründe terleme sonucunda ortaya çıkan su buharını iletme hızı düşük olduğu için, su moleküllerinin çoğu filmden çıkamaz ve paket içerisinde kalır. Bu arada sıcaklıktaki az da olsa değişim sonucu, paket içinde nem yoğuşması meydana gelir. Bunun sonucunda depolanan mantarlarda mikrobiyal bozulma ve yüzey kararması meydana gelmektedir (AyalaZavala ve ark., 2008; Linke ve Geyer, 2013). Dolayısıyla MAP depolamada kullanılan ambalaj malzemesinin özellikleri muhafaza süresi üzerinde etkilidir. Çizelge 2'de i̇stiridye mantarı muhafazasında yaygın olarak kullanılan ambalaj malzemeleri ve depolama sürecinde kalite kaybına etkileri araştırma sonuçlarına dayalı olarak verilmiştir.
MAP'de nem içeriğinin düşürülmesi ile mikrobiyal gelişme engellenir ve böylece renk daha iyi korunduğu için raf ömrü uzatılabilir (Shirazi ve Cameron, 1992). Ambalaj içindeki nem kontrolü, paket içine veya paket malzemesinin yapısına nem absorbe ediciler kullanılarak yapılabilir (Mahajan ve ark., 2008). Bununla birlikte nem absorbe edicilerin kullanımında üründen olabilecek nem kayıpları da dikkate alınmalıdır.

Son yıllarda raf ömrü kısa olan türlerde gıda paketlemede nanoteknolojiden yararlanılmaktadır (Chaudhry ve ark., 2008). Uygulamada nanoteknolojik paket olarak biyolojik film paketleri kullanılmaktadır. $\mathrm{Bu}$ paketler, genellikle biyopolimerler olarak adlandırılan yenilenebilir biyolojik kaynaklardan elde edilmekte, malzemenin ömrünü tamamlaması ile biyolojik olarak parçalanabildikleri için plastik ambalaj malzemelerine kıyasla çevre dostu ürünler olarak kabul edilmektedir. Nanofil polimerlerlerden silikat, kil ve titanyum dioksit $\left(\mathrm{TiO}_{2}\right)$ paketlerin mekanik ve bariyer özelliklerini iyileştirmelerinin yanında gıda paketlemesinde antimikrobiyal ajan, biyosensör ve reaktif oksijen türlerini uzaklaştırma özellikleri de bulunmaktadır (Rhim ve ark., 2013; Syafini ve ark., 2013). Bununla birlikte kullanılan malzemelerin özellikleri mantarların özellikle renk değişimlerini olumlu yönde etkileyebilmektedir.

Mantar muhafazasında kullanılan diğer bir yöntem de kontrollü atmosferde (KA) depolamadır. KA'de depolama, kalite faktörlerinin korunmasında etkili olması ve muhafazada kimyasal madde kullanılmaması nedeniyle mantar muhafazası için de tercih edilebilecek bir yöntemdir. Bugüne kadar Pleurotus türleri kullanılarak yapılan KA'de depolama konusundaki araştırma sonuçları, $\mathrm{O}_{2} / \mathrm{CO}_{2}$ konsantrasyonunun $\% 2 / \% 3$, ortam oransal neminin \%90-95 ve sıcaklığın ise $0^{\circ} \mathrm{C}$ civarında olması ile mantarların 20 günün üzerinde saklanabileceğini göstermektedir (Aslım ve ark., 2011b). KA'de depolama sırasında ağırlık kaybı ve solunum hızı oranı düşmekte, buna bağlı olarak renk, koku ve duyusal kalite değerlerinin daha yüksek ve antioksidan enzim aktivitesinde de artış görüldüğü belirtilmektedir (Li ve ark., 2013). 
Çizelge 2. Pleurotus spp. türlerinde MAP'de depolamanın kaliteye etkisi Table 2. Effects of MAP on quality parameters in Pleurotus spp. species

\begin{tabular}{|c|c|c|c|c|}
\hline $\begin{array}{l}\text { Paket tipi } \\
\text { Package type }\end{array}$ & $\begin{array}{l}\text { Depolama } \\
\text { koşulları } \\
\text { Storage } \\
\text { conditions }\end{array}$ & $\begin{array}{c}\text { DepolamaSüresi } \\
\text { Storage } \\
\text { duration }\end{array}$ & $\begin{array}{l}\text { Araştırma sonuçları } \\
\text { Research results }\end{array}$ & \\
\hline $\begin{array}{l}\text { PVC (Polivinil } \\
\text { klorür), } \\
\text { DYPE (Düşük } \\
\text { yoğunluklu } \\
\text { polietilen), } \\
\text { MPF (Mikro } \\
\text { performanslı film) } \\
\text { PVC (Polyvinyl } \\
\text { chloride), LDPE (Low } \\
\text { Density } \\
\text { Polyethylene), } \\
\text { MPF (Micro } \\
\text { performance film }\end{array}$ & $4^{\circ} \mathrm{C}$ & $\begin{array}{l}7 \text { gün } \\
7 \text { days }\end{array}$ & $\begin{array}{l}\text { - PVC ve DYPE paketlerde } \mathrm{O}_{2} \text { azlığı veya } \mathrm{CO}_{2} \text { fazlalığı } \\
\mathrm{O}_{2} \text { decrease or increase } \mathrm{CO}_{2} \text { in PVC and } L D P E \\
\text { packages } \\
\text { - MPF paketlerde nem yoğuşması } \\
\text { Moisture condensation in MPF packages } \\
\text { - MPF paket içi gaz konsantrasyonunu } 12-15 \mathrm{kPa} \mathrm{O}_{2} \\
\text { ve } 5 \mathrm{kPa} \mathrm{CO}_{2} \text { şeklinde kullanılması } 7 \text { günlük } \\
\text { muhafazada kaliteyi koruma açısından etkili } \\
\text { Gas concentration of } 12-15 \mathrm{kPa} \mathrm{O}_{2} \text { and } 5 \mathrm{kPa} \mathrm{CO}_{2} \\
\text { was effective in terms of keeping quality on } \\
\text { storage for } 7 \text { days in MPF package }\end{array}$ & $\begin{array}{l}\text { Villaescuse } \\
\text { ve Gil, } \\
(2003)\end{array}$ \\
\hline $\begin{array}{l}\text { PVC, } \\
\text { PE (Polietilen), PET } \\
\text { (Polietilen } \\
\text { tereftalat) } \\
\text { PVC, PE } \\
\text { (Polyethylene), PET } \\
\text { (Polyethylene } \\
\text { terephthalate) }\end{array}$ & $\begin{array}{l}0-3^{\circ} \mathrm{C} \\
3-5^{\circ} \mathrm{C} \\
8-10^{\circ} \mathrm{C}\end{array}$ & $\begin{array}{l}3 \text { hafta } \\
3 \text { weeks }\end{array}$ & $\begin{array}{l}\text { - PET }+3 \text { ve }+5^{\circ} \mathrm{C} \text {, renk, su kaybı, mikrobiyal gelişimi } \\
\text { engelleyerek kalitenin korunmasında etkilidir. } \\
\text { PET }+3 \text { and }+5^{\circ} \mathrm{C} \text { are effective in keeping quality } \\
\text { by preventing color, water loss and microbial } \\
\text { growth. }\end{array}$ & $\begin{array}{l}\text { Kumar ve } \\
\text { ark., (2015) }\end{array}$ \\
\hline $\begin{array}{l}\text { PP (Polipropilen) } \\
\text { PP (Polypropylene) }\end{array}$ & $\begin{array}{l}0^{\circ} \mathrm{C} \\
4^{\circ} \mathrm{C}\end{array}$ & $\begin{array}{l}44 \text { gün } \\
44 \text { days }\end{array}$ & $\begin{array}{l}\text { - Renk, parlaklık, sertlik gibi en iyi görsel ve duyusal } \\
\text { kalite kesim yapılmadan } 4^{\circ} \mathrm{C}^{\prime} \text { de depolanan } \\
\text { mantarlarda elde edilmiştir. } \\
\text { The best visual and sensory quality, such as color, } \\
\text { brightness, and firmness was obtained in } \\
\text { mushrooms stored at } 4{ }^{\circ} \mathrm{C} \text { without cutting. }\end{array}$ & $\begin{array}{l}\text { Lee ve ark., } \\
\text { (2012) }\end{array}$ \\
\hline $\begin{array}{l}\text { PVC (14 ve } 16 \mu \mathrm{m}) \\
\text { PVC (14 and } 16 \mu \mathrm{m})\end{array}$ & $\begin{array}{c}0^{\circ} \mathrm{C} \\
\% 90-95 \mathrm{ON}^{*} \\
90-95 \% R H^{*}\end{array}$ & $\begin{array}{l}10 \text { gün } \\
10 \text { days }\end{array}$ & $\begin{array}{l}\text { - } 16 \mu \mathrm{m} \text { kalınlığındaki PVC, renk değişimi, ağılık } \\
\text { kaybı, etilen üretimi ve solunum hızının } \\
\text { yavaşlatılmasında etkili } \\
16 \mu m \text { thick PVC was found effective in decrease of } \\
\text { color change, weight loss, ethylene production and } \\
\text { respiratory rate }\end{array}$ & $\begin{array}{l}\text { Aslım ve } \\
\text { ark., } \\
(2011 a)\end{array}$ \\
\hline $\begin{array}{l}\text { PVC, Polistren } \\
\text { kaplar, PE } \\
\text { PVC, Polystyrene } \\
\text { containers, PE }\end{array}$ & $\begin{array}{c}4{ }^{\circ} \mathrm{C} \\
\% 50-55 \text { ON } \\
50-55 \% R H\end{array}$ & $\begin{array}{l}20 \text { gün } \\
20 \text { days }\end{array}$ & $\begin{array}{l}\text { - PVC kaplarda kalite kayıplarındaki düşüş hızı, } \\
\text { polistren ve PE kaplara göre daha yavaş } \\
\text { Decrease of quality losses in PVC containers is } \\
\text { slower than in polystyrene and PE containers. }\end{array}$ & $\begin{array}{l}\text { Bilgin, } \\
\text { (2015) }\end{array}$ \\
\hline $\begin{array}{l}\text { DYPE } \\
\text { LDPE }\end{array}$ & $\begin{array}{l}2^{\circ} \mathrm{C} \\
4^{\circ} \mathrm{C} \\
8^{\circ} \mathrm{C} \\
\% 87.5 \mathrm{ON} \\
87.5 \% \mathrm{RH}\end{array}$ & $\begin{array}{l}18 \text { gün } \\
18 \text { days }\end{array}$ & $\begin{array}{l}\text { - Tüm sıcaklık düzeylerinde doku sertliğinde artış, } \\
\text { Increased firmness in skin at all temperature levels, } \\
\text { - Sertlikle kitin ve selüloz içeriği az ilişkili, } \\
\text { malondialdehit, elektroliz sızıntı oranı ve toplam } \\
\text { fenolik içeriği ile direkt ilişkili, } \\
\text { Firmness is directly related to malondialdehyde, } \\
\text { electrolysis leakage rate and total phenolic } \\
\text { content, with little association of chitin and } \\
\text { cellulose content } \\
\text { - Sertlikle kararma oranı arasında negatif ilişki } \\
\text { Negative correlation between firmness and } \\
\text { browning rate }\end{array}$ & $\begin{array}{l}\text { Li ve ark., } \\
\text { (2016) }\end{array}$ \\
\hline $\begin{array}{l}\text { PE (Polietilen) kap + } \\
\text { polimerik film } \\
\text { PE (Polyethylene) } \\
\text { container }+ \\
\text { polymeric film }\end{array}$ & $4^{\circ} \mathrm{C}$ & $\begin{array}{l}11 \text { gün } \\
11 \text { days }\end{array}$ & $\begin{array}{l}\text { - Gaz geçirgenliği düşük yoğunlukta olan polimerik } \\
\text { film uygulaması } 11 \text { günlük muhafazada kaliteyi } \\
\text { korumada etkili } \\
\text { Polymeric film application with low density of gas } \\
\text { permeability is effective on keeping quality for } 11 \\
\text { day storage }\end{array}$ & $\begin{array}{l}\text { Sapata ve } \\
\text { ark., (2009) }\end{array}$ \\
\hline
\end{tabular}

*ON: Oransal nem 


\section{c. Işınlama}

İyonize radyasyonla ışınlama yoluyla, gıdaların raf ömrü, gıda kalitesini olumsuz yönde etkilememek koşulu ile uzatılabilmektedir (Anonymous, 2017). Gama Işınlama, duyusal özelliklerde çok az ya da hiç kayıp oluşturmadığı için, gıdaların korunmasında birçok uluslararası kuruluş tarafından onaylanmıştır (Anonymous, 1991; Anonymous, 1992; Anonymous, 1999). Bununla birlikte, mikro besinlerden özellikle de vitaminler ışınlamaya duyarlı olabildiği için, ışınlamada kullanılan etkili dozun belirlenmesinde dikkatli olunması gerekmektedir (Kortei ve ark., 2016).

Yapılan araştırmalar, $P$. eryngii'de, 1 kGy'lik gama ışınlamasının kalite korunmasında 4 hafta süre ile etkili olabileceğini göstermiştir (Akram ve ark., 2012).

\section{d. Kimyasal uygulamalar}

Paketleme dışında mantarlarda enzimatik kararmayı önlemek için kullanılan kimyasal bileşikler son zamanlarda yoğun ilgi görmektedir. Mantarlarda muhafaza ömrünü uzatmak amacıyla sinnamik asit ve türevleri, sorbitol ve sitrik asit kullanılmaktadır. Bu maddelerden sinnamik asit; fenilalanin amino asidinin fenilalanin amonyum liyaz (PAL) enzimi ile parçalanmasından oluşan bir fenolik asittir. Sorbitol ise, glikoz ve fruktozun indirgenmesi ile oluşan 6 karbonlu bir şeker alkoldür. Kristal yapılı, renksiz bir organik asit olan sitrik asit ekşi bir tada sahiptir.

Yapılan araştırmalarda, mantarlarda sinnamik asit ve türevlerinin tirozinaz enzim inhibörlerine karşı oldukça etkili olduğu ortaya konulmuştur (Shi ve ark., 2005). MAP'da nem absorbe edici ajan olan sorbitol ve sitrik asitin birlikte kullanılması ile renk ve su kaybı önemli ölçüde düşürülebilmektedir. Aynı şekilde $M A^{\prime}$ de sorbitol ve $\mathrm{CaCl}_{2}{ }^{\prime}$ ün püskürtme şeklinde uygulanması ile de paket içi nem yoğuşması azaltılabilmektedir. (Anantheswaran ve ark., 1996).

Sitrik asit, gıda endüstrisinde özellikle de metal şelatlama etkisi ile antioksidanlar üzerinde etkili olmaktadır. Ayrıca ortam pH'sını düşürdüğü için gıda endüstrisinde renk koruyucu olarak kullanılmaktadır (Martine ve ark., 2000). Uygulamada, \%0.1-1.0 (v/v) dozları kullanılmaktadır. Sitrik asit ile birlikte \%0.1-3.0 (v/v) dozlarında kalsiyum tozu kullanılması da tekstürü korumada etkili olmaktadır (Wilkinson ve ark., 1988; Jafri ve ark., 2013). Böylece dışsal uygulamalarla mantarlar düşük sıcaklıkta

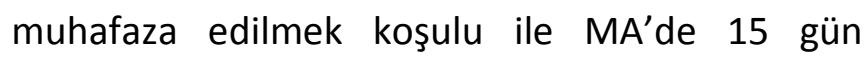
süreyle saklanabilmektedir.

Dışsal uygulamada kullanılan bir diğer kimyasal madde de 1-Metilsiklopropan (1-MCP)'dır. 1-MCP, bahçe bitkileri ürünlerinde etilenin etki mekanizmasını engelleyerek hasat sonrası kalitenin korunmasında etkilidir. $0.3 \mu \mathrm{L} \mathrm{L}^{-1}$ dozunda 1-MCP uygulaması sonrasında $25 \pm 2^{\circ} \mathrm{C}^{\prime}$ de \%70-80 ON'de depolanan mantarlarda ağırlık kaybı ve PPO enzim aktivitesine bağı olan kararma düzeyinde azalma görülmüş ve mantarlar bu koşulda 14 gün süre ile depolanabilmiştir (Zhao ve ark.,2014).

\section{e. Kurutma tekniği}

Mantar muhafazasında mikrobiyal gelişme ve su kaybını azaltma, enzimatik ve biyolojik reaksiyonları yavaşlatma ve de bakteriyel hastalıkların sebep olduğu fizyolojik bozuklukları engellemek ve böylece mantarın raf ömrünü uzatabilmek amacıyla kurutmadan yararlanılmaktadır (Kader ve ark., 1989; Kader, 1992; Roy ve ark., 1995; Salvador ve ark., 2002; Labuza ve ark., 2007). Kurutma, diğer yöntemlere göre daha basit ve pratiktir. Bu işlem sonrasında mantarlar hava geçirmeyen torbalarda yaklaşık 1 yıl kadar muhafaza edilebilmektedir (Bano ve ark., 1992; Rama ve John, 2000). Mantarların kurutulmasında, sıcaklık uygulamaları ve dondurma teknikleri kullanılmaktadır. Sıcaklık uygulaması bütün veya dilimlenmiş mantarların $55-65^{\circ} \mathrm{C}$ sıcak hava üflemesi şeklinde yapılmaktadır (Ekşi, 1980; Doğan ve ark., 2014). Mantarların dondurularak kurutulması işlemi, dondurulmuş üründe bulunan suyun sublimasyon ile uzaklaştırılması temeline dayanmaktadır. Böylelikle mikrobiyal bozulmaların durdurulması sebebiyle yüksek kalite sağlanmaktadır (Ratti, 2001). 


\section{f. Kombine uygulamalar}

Mantarların depolanma ömrünü artırabilmek amacıyla kombine uygulamalar da yapılabilmektedir. Pleurotus ostreatus türü mantarların $50-60^{\circ} \mathrm{C}$ sıcaklıkta kurutulmasının ardından düşük dozlarda $(0,0.5,1,1.5$ ve $2 \mathrm{kGy})$ yapılan gama ışını uygulaması sonrası PE ve PP paketlerde paketlenmesi ile mantarları oda sıcaklığında 12 ay süre ile depolamak mümkün olabilmektedir. Gama ışını uygulamasının özellikle hastalık ve zararlı gelişimini kontrol ederek raf ömrünü uzattığı belirtilmiştir (Kortei ve ark., 2017).

\section{İstiridye mantarında (Pleurotus ostreatus)} paketleme öncesi (DYPE, YYPE, PP ve streç film) sodyum bisülfit $\left(\mathrm{NaHSO}_{3}\right)$ uygulamasının (1000, 2000 ve $3000 \mathrm{ppm}$ ) $10 \pm 2^{\circ} \mathrm{C}$ sıcaklıkta 5 gün süre ile depolanan mantarlarda, $\mathrm{NaHSO}_{3}$ ile $\mathrm{MAP}^{\prime}$ ın birlikte kullanımında, nem içeriği, ağırlık kaybı ve tazelik değerleri üzerinde olumlu etkilerinin olduğu, ancak protein içeriği, lif içeriği, renk değerleri, sülfit kalıntısı, sülfit kokusu ve tekstür üzerinde ise etkili olmadığı belirlenmiştir (Pratama ve ark., 2013). Araştırma sonucunda 1000 ppm $\mathrm{NaHSO}_{3}+$ YYPE kaplar önerilmiştir.

Pleurotus eryngii türü mantarların 20 saat süre ile $1 \mu \mathrm{L} \mathrm{L}^{-1}$ dozunda 1-MCP uygulanması sonrası $30 \mu \mathrm{m}$ kalınlığındaki PP ve MPF filmle kaplanarak $0^{\circ} \mathrm{C}^{\prime}$ de 4 hafta süre ile depolanabileceği, 1-MCP + MPF film ile kaplamanın aroma, sertlik kaybı ve rengin solmasını engellediği belirtilmektedir (Choi ve ark., 2012). Bu sonuçlar, sertlik korunmasına olan etkileri bilinen 1-MCP'nin mantarda da yaygın olarak su kaybına karşı kullanılabileceğini göstermiştir.

Sonuç olarak, mantarların kısa olan hasat sonrası ömürlerini, mantarların düşük sıcaklıklarda MAP koşullarında depolanmasıyla uzatmak mümkün olabilmektedir. Depo ömrünün uzamasında kullanılacak MAP koşullarının, dolayısıyla ambalaj malzemesinin özellikleri önem kazanmaktadır. Illeride yapılacak çalışmalarda çevreyle uyumlu, parçalanabilir ambalaj malzemeleri ile yürütülecek çalışmalar, uygulamada yararlı olabilecektir.

\section{Kaynaklar}

Akram, K., Ahn, J., Yoon, S.R., Kim, G.R., Kwon, J.H., 2012. Quality Attributes of Pleurotus eryngii Following Gamma İradiation. Postharvest Biology and Technology, 66 (1): 42-47.

Anantheswaran, R.C., Beelman, R.B., Roy, S., 1996. Modified Atmosphere and Modified Humidity Packaging of Fresh Mushrooms. Journal of Food Science, 61 (2): 391-397.

Anonim, 2017. https://truefalseistanbul.wordpress.com. Erişim tarihi: 05.02.2017.

Anonymous,

1991.

www.inspection.gc.ca/food/informationforconsumer s/fectsheets/irradiation/1332.

Access date: 20.02.2017.

Anonymous, $1992 . \quad$ http://wwwpub.iaea.org/MTCD/Publications/PDF/te_1213_prn. pdf. Access date: 07.01.2017.

Anonymous, 1999. https://gnssn.iaea.org. Access date: 17.03.2017.

Anonymous, 2016. https://ndb.nal.usda.gov. Access date: 28.12.2016.

Anonymous, 2017. http://www-pub.iaea.org. Access date: 01.04.2017.

Aslım, A.Ş., Acıcan, T., Özelkök, I.S., Soylu, M.K., Akçay, M.E., 2011a. Farklı Modifiye Atmosfer (MA) Uygulamalarının Kayın Mantarının (Pleurotus ostreatus) Hasat Sonrası Fizyolojisi Üzerine Etkileri. Türkiye VI. Ulusal Bahçe Bitkileri Kongresi, 4-8 Ekim, 427-428s. Şanlıurfa.

Aslım, A.Ş., Acıcan, T., Özelkök, I.S., Soylu, M.K., Akçay, M.E., 2011b. Kayın Mantarının (Pleurotus ostreatus) Kontrollü Atmosferde Muhafaza Koşullarının Hasat Sonrası Fizyolojisi Üzerine Etkileri. Türkiye VI. Ulusal Bahçe Bitkileri Kongresi, 4-8 Ekim, 348-349s. Şanlıurfa.

Ayala-Zavala, J.F., Del-Torno-Sanchez, L., Alvarez-Parrilla, E., Gonzalez-Aguilar, G.A., 2008. High Relative Humidity in-Package of Fresh-Cut Fruits and Vegetables: Advantage or Disadvantage Considering Microbiological Problems and Antimicrobial Delivering Systems? Journal of Food Science, 73 (4): 41-47.

Bano, Z., Rajaratham, S., Shashi Rekha, M.N., 1992. Mushroom as The Unconvetional Single Cell Protein for a Conventional Consumption. Indian Food Parker, 46 (5): 20-31.

Bilgin, S.S., 2015. İstiridye Mantarının (Pleurotus ostreatus) Hasat Sonrası Modifiye Atmosfer Koşullarında Kalite Kayıplarının Belirlenmesi. Yüksek Lisans Tezi, Ankara Üniversitesi Fen Bilimleri Enstitüsü, Ankara, 34s.

Brennan, M., Port, G.L., Gormley, R., 2000. Postharvest Treatment with Citric Acid or Hydrogen Peroxide to Extend the Shelf Life of Fresh Sliced Mushrooms. Lebensmittel-Wissenshaft und Technologie, 33: 285289.

Briones, G.L., Varoquaaux, P., Bureau, G., Pascat, B., 1993. Modified Atmosphere Packaging of Common Mushroom. International Journal of Food Science and Technology, 28 (1): 57-68.

Cai, C., Xu, C., Li, X., Ferguson, I., Chen, K., 2006. Accumulation of Lignin in Relation to Change in 
Activities of Lignification Enzymes in Loquat Fruit Flesh After Harvest. Postharvest Biology and Technology, 40 (2): 163-169.

Chaudhry, Q., Scotter, M., Blackburn, J., Ross, B., Boxall, A., Castle, L., Aitken, R., Watkins, R., 2008. Applications and Implications of Nanotechnologies for the Food Sector. Food Additives and Contaminants, 25 (3): 241-258.

Chiron, N., Michelot, D., 2005. Odeurs Des Champignos: Chimie Et Role Dans Les Interactions Biotiques-une Revue. Cryptogamie Mycologie, 26 (4): 299-364.

Choi, M.H., Kim, G.H., 2003. Quality Changes in Pleurotus ostreatus During Modified Atmosphere Storage as Affected by Temperatures and Packaging Material. XXVI International Horticultural Congress: Issues and Advances in Postharvest Horticulture, Acta Horticulture, 12-14 December, Volume 2: pp. 357362, Toronto, Canada.

Choi, J.W., Jhune, J.S., Hong, Y.P., Jho, M.A., Kim, J.K., 2012. Effect of 1-Methylcyclopropene and Microperforated Film Packaging on Postharvest Quality of King Oyster Mushroom (Pleurotus eryngii). Journal of Mushroom Science and Production, 10 (4): 191-197.

Doğan, N., Doğan, C., Hayoğlu, İ., 2014. Farklı Sıcaklık ve Süre Uygulamalarının Pleurotus ostreatus (Istiridye Mantarı)'un Bazı Özelliklerine Etkisi. Harran Tarım ve Gıda Bilimleri Dergisi, 18 (4): 10-16.

Ekşi, A., 1980. Mantarın Gıda Teknolojisinde Başlıca Değerlendirme Alanları ve Konserveye İşlenmesi. Gıda Dergisi, 5 (1-2): 17-23.

Elmastas, M., Isildak, O., Turkekul, I., Temur, N., 2007. Determination of Antioxidant Activity and Antioxidant Compounds in Wild Edible Mushrooms. Jornal of Food Composition Analysis, 20: 337-345.

FAO, 2013. Statistical data of FAO. http://www.fao.org/faostat/en/\#data/TP._Access date: 10.02.2017.

FAO, 2014. Statistical data of FAO. http://www.fao.org/faostat/en/\#data/QC. Access date: 10.02.2017.

Gao, M., Feng, L., Jiang, T., 2014. Browning Inhibition and Quality Preservation of Button Mushroom (Agaricus bisporus) By Essential Oils Fumigation Treatment. Food Chemistry, 149 (1): 107-113.

Gogavekar, S.S., Rokade, S.A., Ranveer, R.C., Ghosh, J.S., Kalyani, D.C., Sahoo, A.K., 2012. Important Nutritional Constituents, Flavour Components, Antioxidant and Antibacterial Properties of Pleurotus sajor-caju. Jounal of Food Science and Technology, 51 (8): 1483-1491.

Jacobsson, A., Brower, J., Amos, N., 2001. Quality Changes of Mushrooms During Storage. IV International Conference on Postharvest Science, Acta Horticulture, 28-30 June, Volume 2: pp. 745-748, Jerusalem, Israel.

Jafri, M., Jha, A., Bunkar, D.S., Ram, R.C., 2013. Quality Retention of Oyster Mushrooms (Pleurotus florida) by a Combination of Chemical Treatments and Modified Atmosphere Packaging. Postharvest Biology and Technology, 76: 112-118.

Jiang, T.J., Luo, Z.S., Ying, T.J., 2015. Fumigation With Essential Oils İmproves Sensory Quality And Enhanced Antioxidant Ability Of Shiitake Mushroom (Lentinus edodes). Food Chemistry, 172: 692-698.
Jolivet, S., Arpin, N., Wichers, H.J., Pellon, G., 1998. Agaricus bisporus Browning: A Review. Mycological Research, 102 (12): 1459-1483.

Kader, A., Zagory, D., Karbel, E.L., 1989. Modified Atmosphere Packaging of Fruits and Vegetables. Critical Reviews in Food Science and Nutrition, 28 (1): 1-30.

Kader, A., 1992. Modified Atmospheres During Transport and Storage. 'Postharvest technology of horticultural crops. (Ed) A.A., Kader., Oakland, California, 85$92 \mathrm{pp}$.

Kalac, P., 2012. A Review of Chemical Composition and Nutritional Value of Wild-Growing and Cultivated Mushrooms. Journal of the Science of Food and Agriculture, 93: 209-218.

Khan, M.A., Tania, M., 2012. Nutritional and Medicinal Importance of Pleurotus mushrooms: An Overview. Food Reviews International, 28 (3): 313-329.

Kortei, N.K., Odamtten, G.T., Obodai, M., Wiafe-Kwagyan, M., Addo, E.A., 2016. Influence of Low Dose of Gamma Radiation and Storage on Some Vitamins and Mineral Elements of Dried Oyster Mushrooms (Pleurotus ostreatus). Food Science and Nutrition, 1: 1-10.

Kortei, N.K., Odamtten, G.T., Obodai, M., Wiafe- Kwagyan, M., 2017. Nutritional Qualities and Shelf Life Extension of Gamma Irradiated Dried Pleurotus ostreatus (Jacq. Ex. Fr.) Kummer Preserved in Two Different Storage Packs. Food Science and Technology, 5 (1): 9-16.

Kumar, P.A., Avinash, R.A., Gol, J.B., Kumar, H.S.A., 2015. Effect of Different Packaging Materials on Shelf Life of Oyster Mushrooms (Pleurotus spp.). Environment and Ecology, 33 (1): 356-361.

Labuza, T.P. and Altunakar, B., 2007. Diffusion and Sorption Kinetics of Water in Foods. Water activity in foods, Fundamental applications. (Ed) G.V.BarbosaCanovas, A.J., Fontana, S.J., Labuza, T.P., Blackwell Publishing Ltd, Oxford, 215-238 pp.

Lee, Y.H., Lee, H.B., Jang, M.J., Ju, Y., Jhune, J.S., 2012. Effect of Trimming Type and Storage Temperature After Harvest on Shelf Life of Pleurotus Eryngii. Journal of Mushroom Science and Production, 10 (4): 198-202.

Li, Y.R., Liu, Q.H., Wang, H.X., Ng, T.B., 2008. A Novel Lectin with Potent Antitumor, Mitogenic and HIV-1 Reverse Transcriptase Inhibitory Activities from the Edible Mushroom Pleurotus citrnopileatus. Biochimica et Biophysica Acta (BBA)-General subjects, 1780 (1): 51-57.

Li, P., Zhang, X., Hu, H., Sun, Y., Wang, Y., Zhao, Y., 2013. High Carbon Dioxide and Low Oxygen Storage Effects on Reactive Oxygen Species Metabolism in Pleurotus eryngii. Postharvest Biology and Technology, 85 (1): 141-146.

Li, D., Qin, X., Tian, P., Wang, J., 2016. Toughening and its Association with The Postharvest Quality of King Oyster Mushroom (Pleurotus eryngii) Stored at Low Temperature. Food Chemistry, 196 (1): 1092-1100.

Linke, M., Geyer, M., 2013. Condensation Dynamics in Plastic Film Packaging for Fruit and Vegetables. Journal of Food Engineering, 116 (1): 144-154.

Mahajan, P.V., Rodrigues, F.A.S., Motel, A., Leonhard, A., 2008. Development of a Moisture Absorber for Packaging of Fresh Mushrooms (Agaricus bisporous). 
Postharvest Biology and Technology, 48 (3): 408414.

Martine, B., Gaelle, L.P., Ronan, G., 2000. Postharvest Treatment with Citric Acid or Hydrogen Peroxide to Extend the Shelf Life of Fresh Sliced Mushrooms. LWT-Food Science and Technology, 4 (33): 285-289.

Nerya, O., Ben-Arie, R., Luzzatto, T., Musa, R., Khativ, S., Vaya, J., 2006. Prevention of Agaricus bisporus Postharvest Browning with Tyrosinase Inhibitors, Postharvest Biology and Technology, 39 (3): 272-277.

Popa, M., Stanescu, D., Heraseu, M., Ilie, A., Dumitreseu, R., Vraei, I., 1999. Some Aspects Regarding Modified Atmosphere Packaging of Mushrooms. Agri Food Quality II, Royal Society of Chemistry. (Ed) Hagg, M., Ahvenainen, R., Evers, A.M., Tiilikkala, K. Cambridge, UK, 229: 177-181.

Pratama, D., Suhaidi, I.., Julianti, E., 2013. The Effect of Sodium Bisulphite and Packaging Materials on Quality of Oyster Mushroom (Pleurotus ostreatus) in cold storage. Journal Rekayasa Pangan dan Pertanian, 1 (3): 17-24.

Rama, V., John, P.J., 2000. Effects of Metods of Drying and Pretreatments on Quality of Dehydrated Mushroom. Indian Food Packer, 54 (5): 59-64.

Ratti, C., 2001. Hot-air and Frezee-drying of High Value Foods. Journal of Food Engineering, 49: 311-319.

Rhim, J.-W., Park, H.-M., Ha, C.-S., 2013. Bionanocomposites for food packaging applications. Progress in Polymer Science, 38 (10-11): 1629-1652.

Roy, S., Anantheswaran, R.C., Beelman, R.B., 1995. Fresh Mushrooms Quality as Affected by Modified Atmosphere Packaging. Journal of Food Science, 67 (2): 334-340.

Salvador, M.L., Jaime, P., Oria, R., 2002. Modeling of $\mathrm{O}_{2}$ and $\mathrm{CO}_{2}$ Exchange in Modified Atmosphere Packaging of Burlat Cherries. Journal of Food Science, 67 (1): 231240.

Sapata, M., Ramos, A., Ferreira, A., Andrada, L., Candeias, M., 2009. Quality Maintenance Improvement of Pleurotus ostreatus Mushrooms By Modified Atmosphere Packaging. Acta Scientiarum Polonorum Technologia Alimentaria, 8 (2): 53-60.

Shi, Y., Chen, Q.X., Wang, Q., Song, K.K., Qiu, L., 2005. Inhibitory Effects of Cinnamic Acid and İts Derivatives an the Diphenolase Activity of Mushroom (Agaricus bisporus) Tyrosinase. Food Chemistry, 92 (4): 707-
712.

Shirazi, A., Cameron, A.C., 1992. Controlling Relative Humidity in Modified Atmosphere Packages of Tomato Fruit. HortScience, 27 (4): 336-339.

Song, L., Chen, H., Gao, H., Fang, X., Mu, H., Yuan, Y., Yeng, Q., Quan, J., 2013. Combined Modified Atmosphere Packaging and Low Temperature Storage Delay Lignification and Improve the Defense Response of Minimally Processed Water Bamboo Shoot. Chemistry Central Journal, 7 (1): 147-155.

Stamets, P., 2005. Notes on Nutritional Properties of Culinary-Medicinal Mushrooms. International Journal of Medicinal Mushrooms, 7 (1-2): 103-110.

Syafini, G.N., Zaulia, O., Aisyah, A.S., Azhar, M.N., Rohaya, M.A., Habsah, M., Zaipun, M.Z., Tham, S.L., 2013. Quality Maintenance of Grey Oyster Mushroom (Pleurotus ostreatus) by Nanosilver Packaging and Ethylene Absorbers. Acta Horticulture, Proc. $7^{\text {th }}$ International Postharvest Symposium, 25-29 June, Volume 1: pp. 1341-1346. Kuala Lumpur, Malaysia.

TÜik, 2015. Türkiye İstatistik Kurumu Verileri. http://rapory.tuik.gov.tr/7487264643164747858922 13179.html. Erişim tarihi: 05.02.2017.

Wang, H.X., Ng, T.B., 2004. Purification of A Novel LowMolecular Mass Laccase With HIV-1 Reverse Transcriptase Inhibitory Activity From The Mushroom Tricholoma giganteum. Biochemistry and Biophysics Research Communication, 315 (2): 450454.

Wilkinson, B.H.P., Barret, S.M., Deuel, C.L., 1988. Texture Stable Food Product. Patent Application Number: EP19870309411, patent date: 4 May 1998.

Villaescusa, R., Gil, M.I., 2003. Quality Improvement of Pleurotus Mushrooms By Modified At Mosphere Packaging and Moisture Absorbers. Postharvest Biology and Technology, 28 (1): 169-179.

Zhao, C., Zhao, L., Pi, Y., Wu, X., Ma, F., 2014. The Influence of Storage Quality of Pleurotus Eryngii by 1Methylcyclopropene Treatment. Applied Mechanics and Materials, 675-677: 1685-1690.

Zivanovic, S., Buescher, R.W., Kim, K.S., 2000. Textural Changes in Mushrooms (Agaricus bisporus) Associated with Tissue Ultrastructure and Composition. Journal of Food Science, 65 (8): 14041408. 